\title{
ESTRUTURAÇÃO DO ARCO DE RIO GRANDE E DA SINCLINAL DE TORRES, BACIA DO PARANÁ, RS: EVIDÊNCIAS POR LEVANTAMENTOS MAGNETOTELÚRICOS
}

\author{
Philipp, R.P. ${ }^{1}$; Rolim, S.B.A. ${ }^{1}$; Malta, L. ${ }^{2}$; Jelinek, A.R. ${ }^{1}$; Viana ${ }^{4}$, A.; Lavina, E. ${ }^{3}$; Cagliari, J. ${ }^{2}$; Faccini, U.F. ${ }^{3}$
}

\section{INTRODUÇÃO}

O presente trabalho apresenta os primeiros resultados da modelagem de dados magntotelúricos e análise integrada com informações geológicas, estruturais e geofísicas (sensoriamento remoto, gravimetria e magnetometria) na caracterização de estruturas de rifteamento, estratigrafia e intrusões, presentes na porção sul-sudeste da Bacia do Paraná, RS.

O método Magnetotelúrico (MT) utiliza como fonte o campo magnético natural da Terra, o qual induz um campo elétrico de acordo com as leis de Maxwell. O MT é muito utilizado em áreas com cobertura de basalto, carbonatos e sal, estruturas resistivas, geralmente de alta velocidade, que causam problemas para o imageamento com dados sísmicos. Além disso, possui excelente relação custo $x$ benefício, tornando-se uma ferramenta de alto desempenho e rápida execução com grande potencial de investigação de crosta e manto, inclusive no meio oceânico, sendo empregado na indústria petrolífera e na exploração de minerais metálicos sulfetados.

Mais especificamente, este trabalho teve como objetivo a identificação de estruturas do Escudo Sul-riograndense, principalmente, o comportamento destas abaixo dos derrames basálticos da Formação Serra Geral através das seções geofísicas do método MT e de sua consequente modelagem geomorfológica.

\section{ÁREA DE ESTUDO}

A área de estudo envolve todo o estado do Rio Grande do Sul (Figura 1), onde foram realizados três perfis regionais envolvendo um total de cerca de $1150 \mathrm{~km}$ de extensão. Os levantamentos foram realizados segundo a direção NE-SW e NW-SE.

\section{METODOLOGIA}

A aquisição de dados pelo método magnetotelúrico envolveu a obtenção de dados de três seções regionais com extensões de 520 km (PSI), 270 km (PSII) e 355 $\mathrm{km}$ (PSIII). O espaçamento entre as estações foram definidos em função da profundidade estimada do embasamento e do grau de detalhamento a ser investigado em cada área do trabalho.

O Perfil PSI foi traçado da cidade de Aceguá (RS) até a cidade de Barracão (SC), ao longo da calha do Rifte Guaritas, sendo constituído por 68 estações (PSI-1 a PSI-69). As estações PSI-1 a PS-16 e PSI-23 a PSI-46 foram levantadas com um espaçamento de $5 \mathrm{~km}$ entre si. Entre as estações PSI-16 e PSI-23 o espaçamento foi definido em $15 \mathrm{~km}$ e por fim, as estações PSI-46 a PSI-69 foram levantadas com espaçamento de $10 \mathrm{~km}$.
O Perfil PSII estende-se da cidade de Vacaria até Frederico Westphalen, sendo constituído por 54 estações (PSII-1 a PSII-55) espaçadas de $5 \mathrm{~km}$. O Perfil PSIII foi traçado da cidade de Nonoai até Manoel Viana, incluindo 50 estações (PSIII-1 a PSIII-51) espaçadas de $7 \mathrm{~km}$. Ambos perfis são sobre as rochas vulcânicas da Formação. Serra Geral.

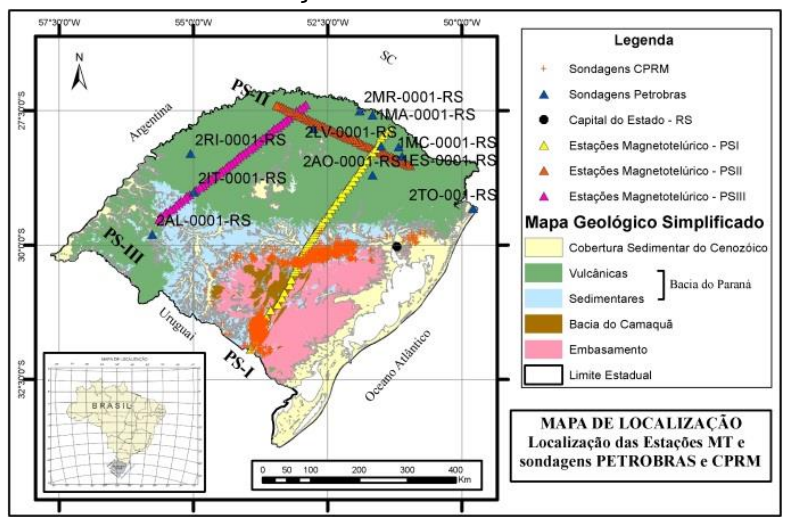

Figura 1 - Mapa geológico simplificado do RS com a localização das seções de levantamento e respectivas estações geofísicas.

O método magnetotelúrico (MT) mede os campos elétricos e magnéticos na superfície terrestre para obtenção do tensor de impedância e dos valores de resistividade aparente e fase. O método utiliza a variação temporal natural do campo magnético da Terra. Essas variações englobam a faixa de frequência desde $0.001 \mathrm{~Hz}$ até cerca de $100 \mathrm{KHz}$. Os canais telúricos (campo elétrico Ex e Ey) são medidos com dipolos de $100 \mathrm{~m}$ em configuração cruzada utilizando eletrodos de cloreto de chumbo ( $\mathrm{PbCl} 2)$. Os campos magnéticos $(\mathrm{Hx}, \mathrm{Hy})$ são registrados com o uso de bobinas de indução de alta sensibilidade. Os campos elétricos $(E)$ e magnéticos $(H)$ ortogonais registrados são alinhados para norte magnético (Ex, Hy) e leste (Ey, Hx) magnéticos.

Para a aquisição dos dados de MT foram utilizados dois equipamentos de medidas magnetotelúrica de banda larga, modelo MTU-5A, da marca Phoenix Geophysics do Canadá (Phoenix, 1990). As estações foram programadas para 21 horas de coleta, o que permite uma boa aquisição de dados em alta profundidade, podendo alcançar até $10 \mathrm{~km}$. Foram utilizados dois equipamentos simultaneamente, o que permitiu a remoção de feições espúrias geradas por ruídos eletromagnéticos produzidos pelo meio (cercas elétricas, redes de alta tensão, veículos e pessoas). 0 processamento dos dados obtidos foi efetuado pela empresa geofísica Stratalmage utilizando programas 
próprios do fabricante (Phoenix) resultando em curvas de resistividade aparente e fase, tipper, e inversão 2D. A interpretação dos resultados nas seções baseou-se na diferenciação de valores de resistividade apresentados com sua assinatura obtida da identificação litológica encontrada nos testemunhos de sondagens (principalmente os 4 testemunhos de sondagem da Petrobrás: 2RD01RS, 2LV01RS, 1MC01RS E 2IT01RS). Valores de baixa resistividade (abaixo de $35 \mathrm{Ohms} / \mathrm{m}$ ) são atribuídos a rochas sedimentares. Moderados a altos (intervalo de 35 a 600 Ohms $/ \mathrm{m}$ ) constituem uma faixa ampla de litologias diferenciadas. Nesta porção englobam-se tanto rochas sedimentares secas (com seus interstícios não preenchidos por fluidos) até rochas ígneas e plutônicas intemperizadas ou fraturadas. Por fim, as faixas de alta resistividade (valores acima de 600 Ohms/m) são representadas pelas rochas plutônicas ou metamórficas sem alterações (rocha sã).

Para o reconhecimento da assinatura do sinal geofísico (atribuição do sinal físico à rocha) utilizou-se parte das 1748 testemunhos de sondagens presentes na área de estudo. Desta maneira pode-se relacionar o sinal de resistividade com a litologia associada na região. É necessário reconhecer que estes valores não são absolutos e não podem ser interpretados de forma abrupta no método MT. Além dos valores pontuais de resistividade de cada estação estarem dentro de uma margem de erro pós-processado na inversão 2D (erro de 250 metros), o método MT apresenta uma linha de tendência. Em outras palavras, onde se identifica uma mudança de valores de resistividade é considerado indício da presença de contato litológico. As seções bidimensionais foram produzidas pela empresa Stratalmage com os programas computacionais específicos de inversão 2D da Empresa Phoenix. Já a modelagem tridimensional, foi realizada através do programa computacional RECON (RECON, 2011).

Para efetuar a composição da modelagem tridimensional, além do sinal geofísico, foram utilizados dados de 4 testemunhos de sondagem cedidos pela Petrobrás e de 1744 testemunhos cedidos pela CPRM.

\section{RESULTADOS}

Dos perfis geofísicos elaborados (PS-I: Figura 2, PSII2: Figura 3 e PS-III: Figura 4), os contatos existentes nas estações foram interpretados em função do grau de resistividade aparente da rocha com a geologia do local. Como o MT é um método suavizado e não abrupto, a delimitação ficou restrita às zonas iniciais de variação dos sinais de mínimo para máximo e viceversa. Os falhamentos e fraturas superficiais tiveram sua projeção coletada a partir do mapa geológico do estado do Rio Grande do Sul. Já os profundos foram marcados com apoio individual dos sinais do modo TE (transverse electric) e TM (transverse magnetic) de cada estação. A interpretação é resultado da divergência das curvas. Onde as curvas dos modos se afastavam umas das outras é indicativo de que naquela profundidade tem-se uma descontinuidade de camadas. As descontinuidades mais visíveis estão relacionadas a zonas de falhas que delimitam estruturas maiores, relacionadas à grabens e horsts. A morfologia do embasamento evidencia bem essas feições.

As seções PS-I e PS-III possuem direção NE-SW e ressaltam as falhas de direção NW-SE, enquanto a seção PS-II possui direção NW-SE e destaca as falhas de direção NE-SW. As falhas observadas em geral mostram superfícies de falhas com disposição subvertical e apresentam rejeitos de algumas centenas de metros.

Após a interpretação das seções foi gerado no programa computacional RECON o mapa de superfície total do embasamento (Figura 5).

\section{Falhas NW-SE}

A observação das seções PS-I e PS-III destaca a presença de importantes falhas de direção NW-SE e ressaltam a presença de duas grandes estruturas regionais: (i) o Arco de Rio Grande na porção sul e (ii) o Sinclinal de Torres na sua extremidade norte (Holz et al. 2010). Os rejeitos das falhas não são proeminentes e possuem em geral, entre 300 e 1000 metros.

O Arco de Rio Grande é um horst de dimensão regional onde se destaca o soerguimento do embasamento e o aumento da espessura das camadas de rochas sedimentares da Bacia do Paraná nos extremos sul e norte desta estrutura. A estrutura do arco esta delimitada ao norte pelo Sistema de Falhas JaguariMata e ao sul pelo Sistema de Falhas Alegrete e Ibaré. Estas evidências sugerem que o arqueamento ocorreu simultaneamente à deposição de parte das sequências sedimentares da Bacia do Paraná. Dados estratigráficos, associados à arquitetura de fácies Faccini, 2000; Faccini et al 2003) e dados geocronológicos e termocronológicos corroboram esta hipótese e têm demonstrado que a estruturação deste arco é contemporânea com a deposição dos sedimentos triássicos do Grupo Rosário do Sul (Faccini, 2000, 2007; Philipp et al. 2013a,b; Jelinek et al. 2013). Do mesmo modo, as ocorrências da Formação Guará, restrita a porção sul do arco, com paleocorrentes para sul (Faccini, 2000, Scherer \& Lavina, 2005) e da Formação Caturrita, restrita ao norte do arco e com paleocorrentes para norte (Faccini, 2000), indicam que o soerguimento do arco se estendeu até o início do Jurássico. A integração das informações das seções PS-I e PS-III mostra que a estrutura do arco diminui sua largura e dimensão em direção ao oeste do Rio Grande do Sul. 


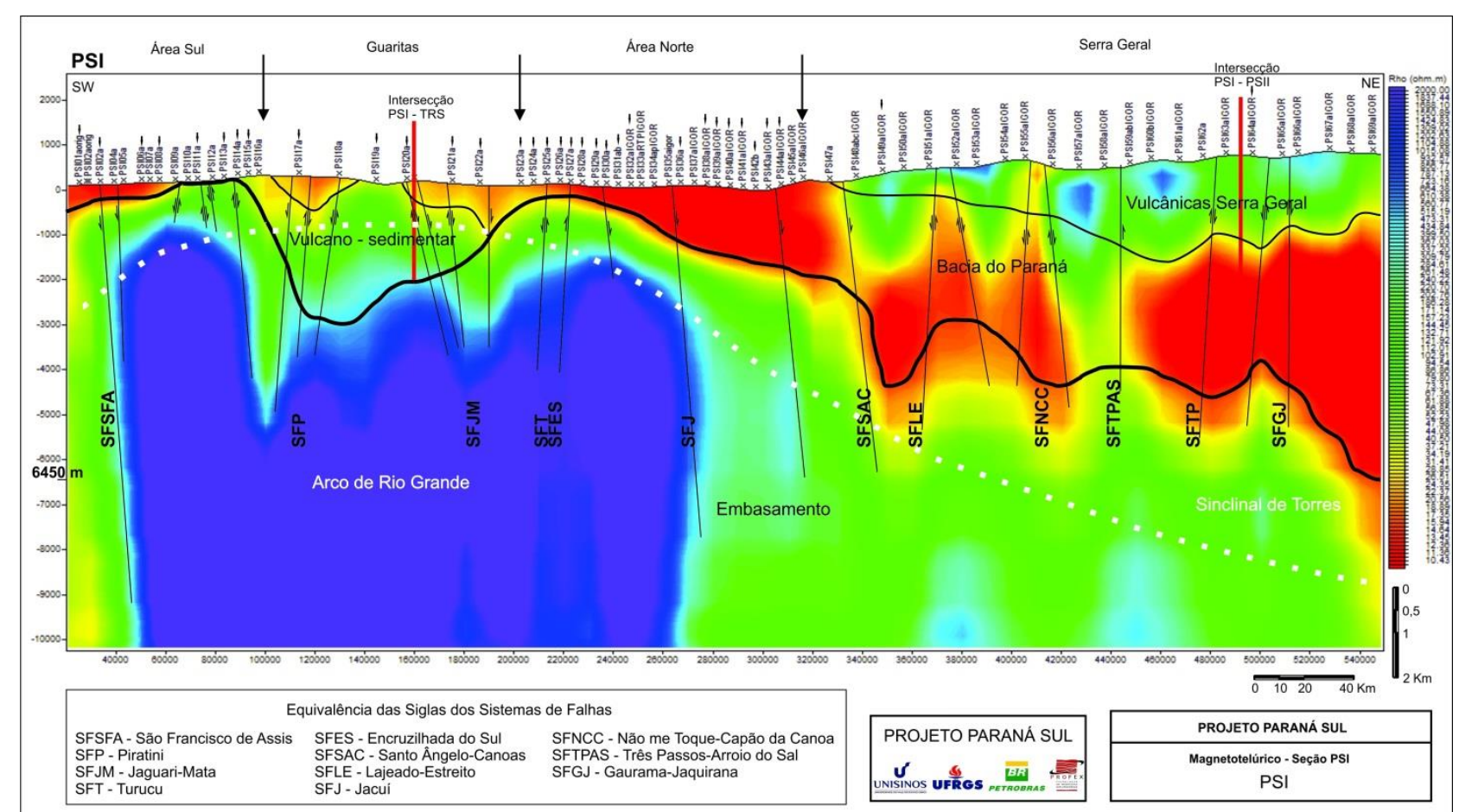

Figura 2 - Seção MT PSI, ao longo da calha do Rifte Guaritas, evidenciando a ação dos sistemas de falhas NW estruturando o embasamento e o espessamento para $\mathrm{N}$ dos depósitos preservados da Bacia do Paraná nas depressões geradas. $\mathrm{O}$ espessamento maior no extremo NE da figura corresponde à borda sul da Sinclinal de Torres.

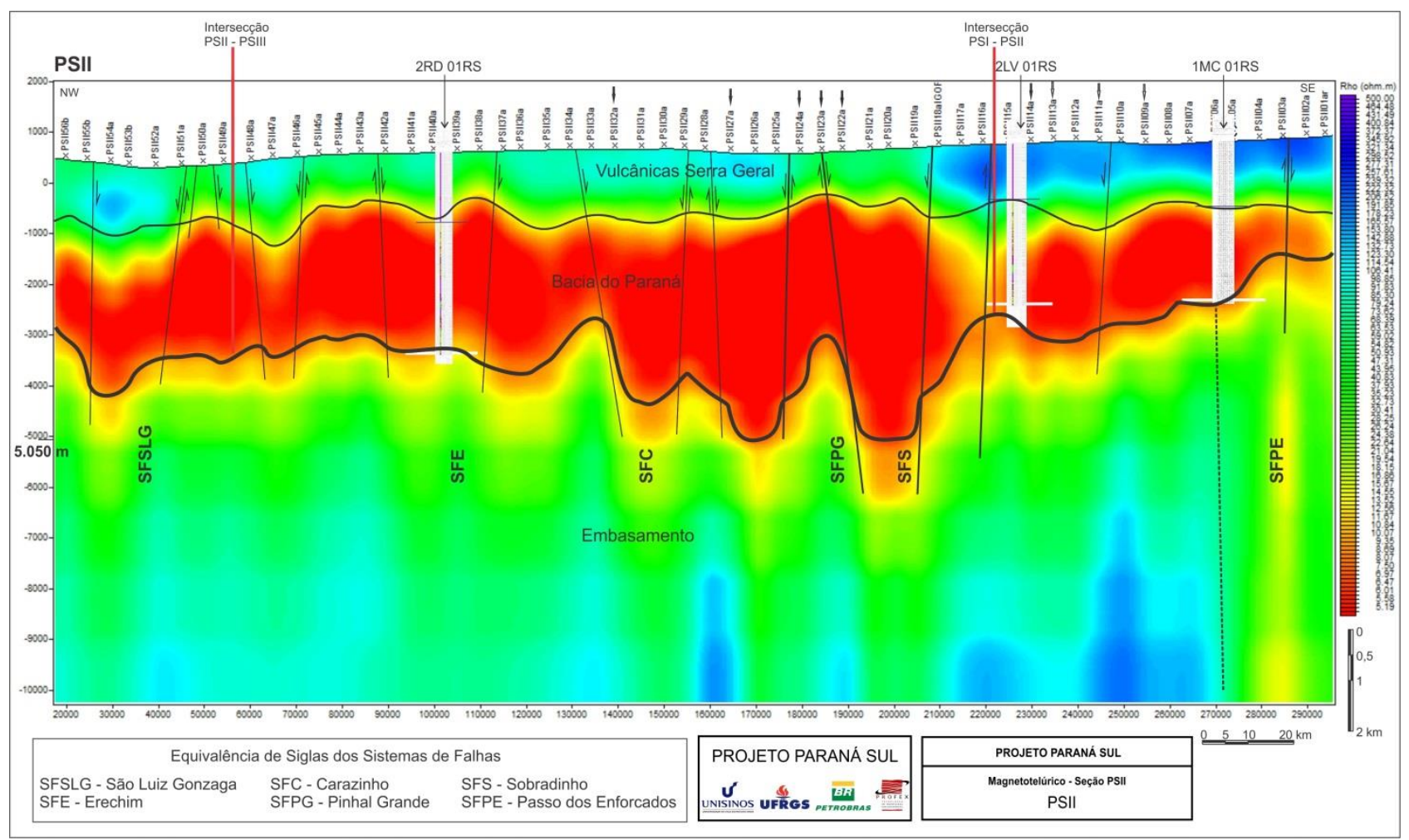

Figura 3 - Seção MT PSII, no sentido NW-SE, sobre os vulcanitos da Formação Serra Geral no Norte do Estado do RS, mostrando a morfologia do embasamento e preservação dos depósitos da Bacia do Paraná, produzidas pela ação dos sistemas de falhas NE. A interpretação foi balizada pelos poços da Petrobras, indicados na Figura. 


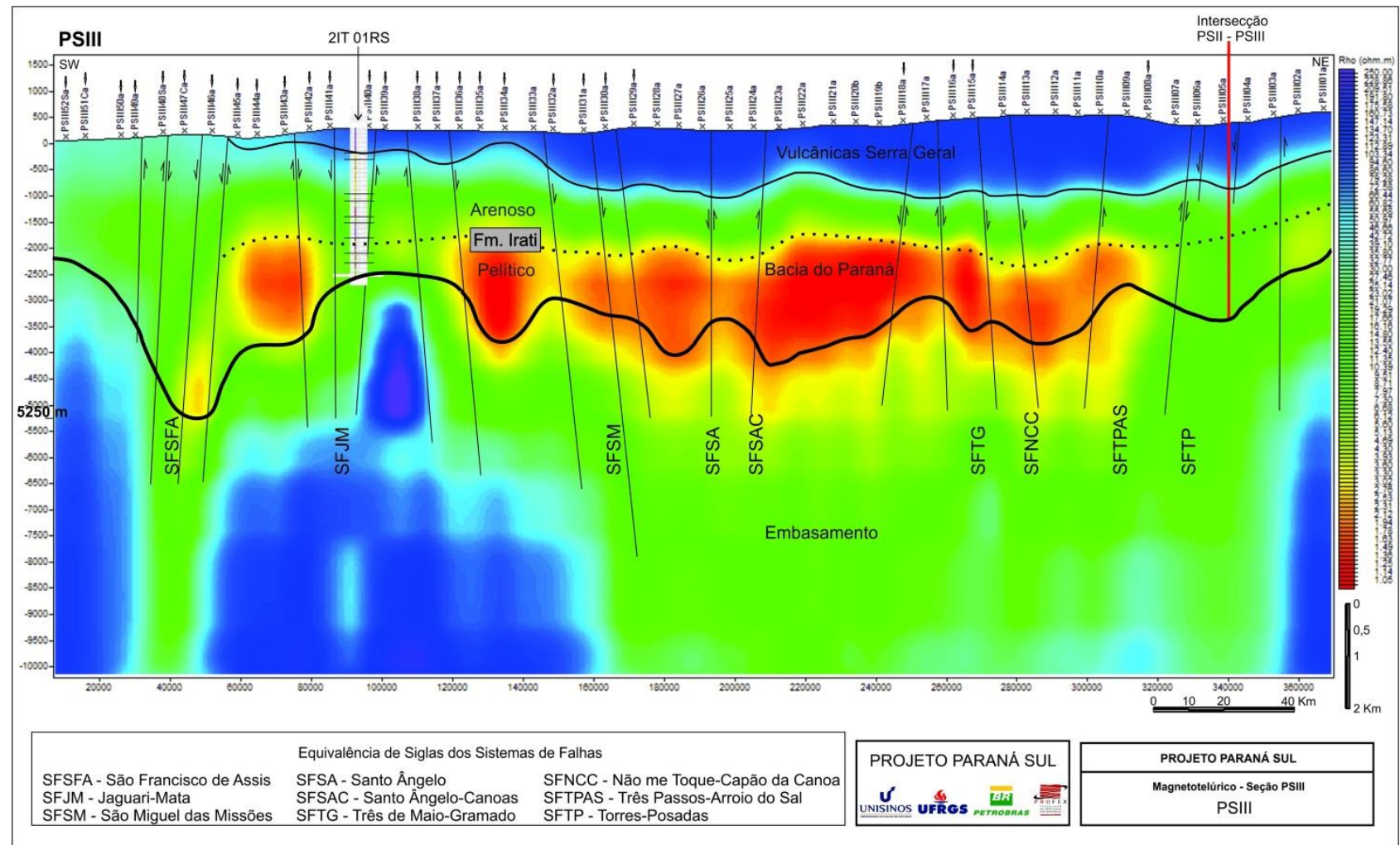

Fig.4 - Seção MT PSIII, de direção NE-SE no oeste do Estado do RS, cortando os sistemas de falhas NW. A interpretação é balizada nesta seção por apenas um poço da Petrobras. Notar, entretanto, no extremo SW da seção, a profunda depressão delimitada pelos sistemas de falhas São Francisco de Assis (SFSA) e Jaguari-Mata (SFJM). Na modelagem 3D, apresentada mais adiante, esta depressão mostra uma conexão da Bacia do Paraná na fronteira oeste do RS com a bacia do Chaco Paraná, na Argentina

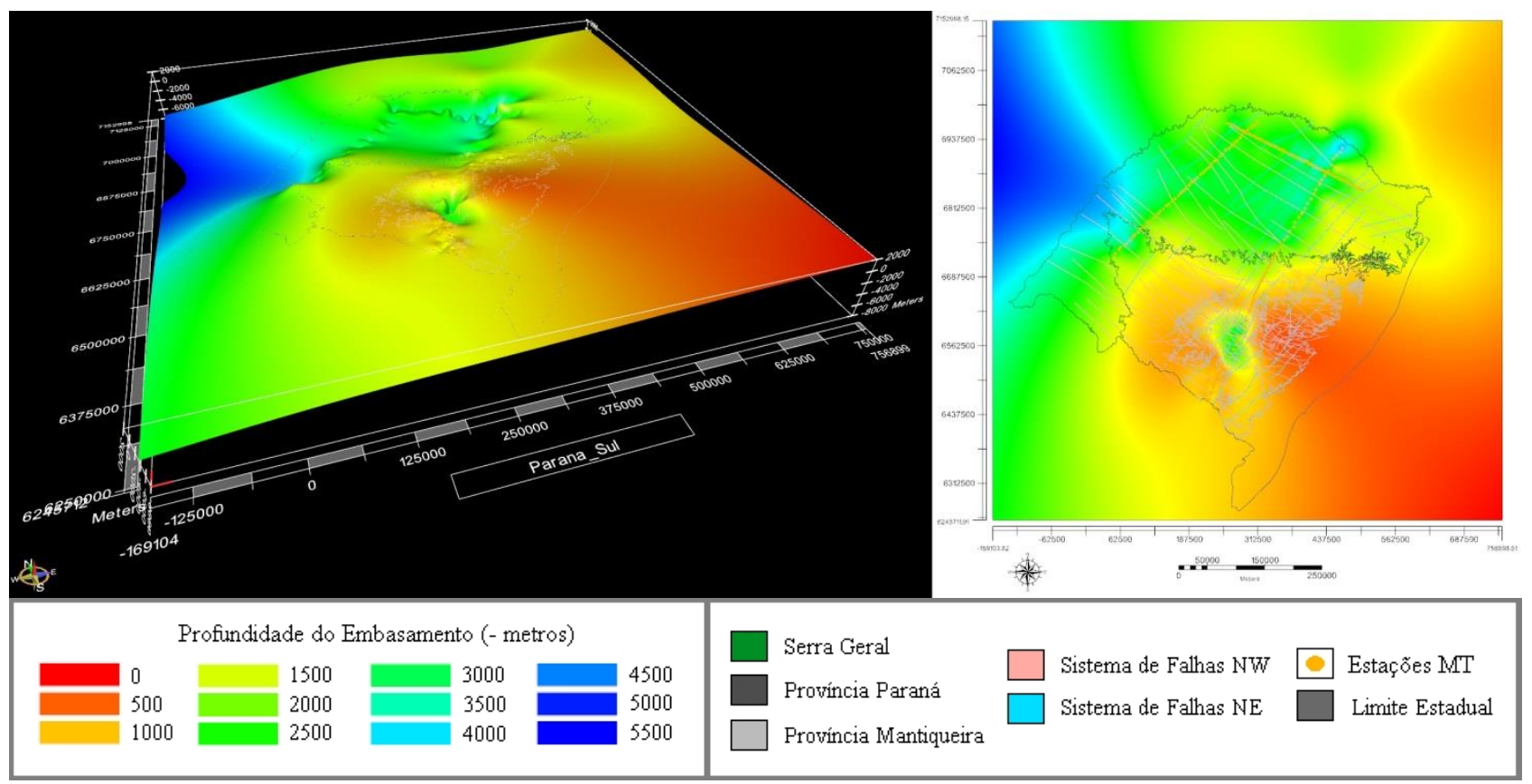

Figura 5 - Modelo 3D (esquerda) do embasamento no sul do Brasil, gerado com base em informações de poços e integração das seções de MT realizadas. A direita, vista em planta, ressaltado o contorno do Estado do RS. 
A Sinclinal de Torres é uma estrutura caracterizada pelo aumento de espessura das camadas sedimentares da Bacia do Paraná em direção ao norte da seção. Do mesmo modo observa-se que a continuidade das camadas é interrompida por grandes sistemas de falhas regionais, destacando-se as Falhas Torres-Posadas, Não-me-Toque/Capão da Canoa e Santo Angelo-Barra do Ribeiro. As falhas que afetam a Sinclinal de Torres afetam também as rochas vulcânicas da Formação Serra Geral, indicando que os falhamentos estiveram ativos pós-Cretáceo.

\section{Falhas NE-SW}

A observação da seção PS-II destaca a presença de uma grande quantidade de falhas de direção NE-SW, que em sua grande parte representam a reativação das estruturas dúcteis impressas nas rochas do Escudo Sul-rio-grandense, que constituem o embasamento da Bacia do Paraná. O aumento localizado da espessura das camadas sedimentares da Bacia do Paraná sugere que parte destas falhas estiveram ativas durante a deposição da bacia.

\section{CONCLUSÕES}

Os modelos obtidos até o momento pelos dados MT apoiam os modelos da geologia conhecida na área e trazem novas informações sobre as partes mais profundas da Bacia do Paraná no Estado do Rio Grande do Sul.

Em geral os dados apresentaram excelente qualidade e comportamento típico do ambiente de aquisição desde a porção sul Bacia do Paraná, passando pelo Rifte Guaritas e retomando a bacia já na sua porção mais profunda e atingindo a parte mais espessa do derrame da Formação Serra Geral, ao norte do RS. A PSII esteve inteiramente dentro do ambiente geológico da Bacia do Paraná apresentando os sedimentos condutivos mais espessos e as rochas básicas intrusivas mais próximas a superfície. A PSIII teve seu início no mesmo domínio da PSIl e ao final, ao sul, é possível notar 0 afinamento sedimentar e a aproximação da borda SW da bacia. A presença de uma possível "calha" pode ser observada na parte central do perfil, bem como uma zona de cisalhamento no final do mesmo.

A modelagem geológica integrada (MT, análise estrutural e estratigráfica) mostra, em escala regional, uma nova paleogeografia. Para a região oeste do Rio Grande do Sul, região de Alegrete-São Francisco de Assis, indica a existência de um vale profundo (mais de $3 \mathrm{~km}$ ) orientado para W-NW, aberto para a Argentina.

$\mathrm{Na}$ área Sul, região de Bagé-Hulha Negra, alinhado com a direção geral do Rifte Guaritas, foi detectado um paleovale com abertura para sul (Uruguai) onde o equivalente do Grupo Itararé (Formação San Gregorio) apresenta fácies marinhas, com presença de amonóides (Closs, 1967; de Santa Ana et al., 2006), indicando conexão com o oceano nesta região.
Para norte do Estado, em direção a Santa Catarina, mostra um conjunto de depressões alinhadas com o eixo do Rifte Guaritas, sugerindo repercussões a serem futuramente estudadas.

\section{REFERÊNCIAS}

CLOSS, D. 1967. Orthocone Cephalopods from the Upper Carboniferous of Argentina and Uruguay. Ameghiniana, 5, 123-129.

de SANTA ANA, H., GOSO, C. \& DANERS, G. 2006. Cuenca Norte: Estratigrafía del Cabonífero- Pérmico. In: VEROSLAVSKY, G., UBILLA, M., MARTíNEZ, S. (Eds.): Cuencas Sedimentarias de Uruguay Paleozoico. DIRAC Facultad de Ciencias, Montevideo, $325 p$.

FACCINI, U.F., 2000. Estratigrafia do permo-triássico do Rio Grande do Sul: estilos deposicionais versus espaço de acomodação. Porto Alegre. Tese de Doutorado, Programa de Pós-graduação em Geociências, Instituto de Geociências, UFRGS, 332p.

FACCINI, U.F.; GIARDIN, A.; MACHADO, J.L.F.2003. Heterogeneidades litofaciológicas e hidroestratigrafia do Sistema Aquífero Guarani na região central do estado do Rio Grande do Sul, Brasil. in: PAIM, P.S.G; FACCINI, U.F.; NETTO, R.G. (Ed.). Geometria, arquitetura e heterogeneidades de corpos sedimentares. São Leopoldo, UNISINOS, p. 147-173.

FACCINI.U.F. 2007. Tectonic and climatic induced changes in depositional styles of the Mesozoic sedimentary record of Southern Paraná Basin, Brazil. Problems in Western Gondwana Geology I, Gramado, Extended Abstracts. http://www.ufrgs.br/alpp/Problems_Gondwana.pdf

HOLZ, Michael ; KALKREUTH, W. ; ROLIM, S. B. A. . Coal resources off-shore Brazil a speculative play for coal bed. Marine and Petroleum Geology, v. 27, p. 1119-1132, 2010.

JELINEK, A.R.; PHILIPP, R.P.; CHEMALE Jr., F. 2013. Evolução termo-tectônica do Cinturão Dom Feliciano no RS e SC a partir da integração da análise por traços de fissão em apatita e da geologia estrutural. Simpósio Nacional de Estudos Tectônicos, XIV, SBG, Chapada dos Guimarães, Boletim de Resumos Expandidos.

PHILIPP, R.P.; KLOSS, H.P.; SCHULTZ, C.L.; BASEI, M.A.S.; HORN, B.L.; SOARES, M. 2013a. Proveniência por U-Pb LA-ICP-MS em zircão detrítico e idade de deposição da Formação Santa Maria, Triássico da Bacia do Paraná, RS: evidências da estruturação do Arco do Rio Grande. Simpósio Nacional de Estudos Tectônicos, XIV, SBG, Chapada dos Guimarães, Boletim de Resumos Expandidos. 
PHILIPP, R.P.; ZVIRTES, G.; BRUCKMANN, M.P.; FACCINI, U.F.; VIANA, A.R.; LAVINA, E.; SCHERER, C.. 2013b. Estruturas tectônicas na seção geológica Santana do Livramento-Rosário do Sul-Jaguari: evidências do Arco de Rio Grande, Bacia do Paraná, RS. Simpósio Nacional de Estudos Tectônicos, XIV, SBG, Chapada dos Guimarães, Boletim de Resumos Expandidos.

PHOENIX, 1990. Phoenix Geophysics, 3781 Victoria Park Avenue, Unit 3 Toronto, Ontario, Canada M1W $3 \mathrm{~K} 5$.

RECON, 2011. Austin GeoModeling, Inc. 1996-2014. 6500 River Place Blvd Building 4, Suite 107 Austin, Texas 78730 USA.

SCHERER, C. M. \& LAVINA, E.L.C. 2005. Sedimentary cycles and facies architecture of aeolianfluvial strata of the Upper Jurassic Guara' Formation, southern Brazil. Sedimentology, 52: 1323-1341. 